\title{
ASSESSMENT OF EXTRACT OF Musa paradisiaca Linn. IN PRODUCING NANOPARTICLES TO ENHANCE QUALITY OF NYLON FABRIC
}

\author{
E. Rohaeti ${ }^{1, *}$, K. S. Budiasih ${ }^{1}$, A. Rakhmawati ${ }^{2}$, E. Nuraini ${ }^{3}$ \\ and C. Kusumastuti ${ }^{1}$ \\ ${ }^{1}$ Department of Chemistry Education, Faculty of Mathematics and Natural Sciences, UNY, \\ Yogyakarta, Indonesia 55281 \\ ${ }^{2}$ Department of Biology Education, Faculty of Mathematics and Natural Sciences, UNY, \\ Yogyakarta, Indonesia 55281 \\ ${ }^{3}$ Politeknik ATK, Yogyakarta, Indonesia \\ *E-mail: eli_rohaeti@uny.ac.id
}

\begin{abstract}
Modification of Nylon fabrics with HDTMS compound and silver nanoparticles which prepared via bio-reduction method using banana peel extract (Musa paradisiaca Linn.) has been conducted in this research. That modification can increase the quality of Nylon fabrics so they have antibacterial and self-cleaning properties. The types of Nylon fabrics in this research are Nylon fabric (Ny0), Nylon-Ag (Ny1), Nylon-HDTMS (Ny2), Nylon-Ag-HDTMS (Ny3), and Nylon-HDTMS-Ag (Ny4). The silver nanoparticles were characterized by using spectrophotometry of UltraViolet-Visible. Antibacterial activity against gram-positive and gram-negative bacteria was analyzed by measuring the clear zone around the sample. While the contact angle test was performed by the sessile drop method. Silver nanoparticles have a maximum peak at the wavelength of $440.50 \mathrm{~nm}$. Nylon-Ag shows the highest antibacterial activity against E.coli and $S$. aureus. The inhibition zone of Nylon-Ag at 54 hours of incubation time is 97 times higher than the inhibition zone of Nylon without modification at 24 hours of incubation against E.coli. Likewise, with the inhibition capacity of Nylon-Ag in inhibiting the growth of S. aureus, Nylon-Ag has antibacterial activity at 72 hours incubation time of 85 times higher than Nylon at 48 and 72 hours incubation. However, NylonHDTMS-Ag has the greatest contact angle, that was $110.63^{\circ}$
\end{abstract}

Keywords: Antibacterial Activity, Banana Peel, Contact Angle, Nylon Fabrics, Silver Nanoparticles

(C) RASĀYAN. All rights reserved

\section{INTRODUCTION}

In recent years not only textiles with antibacterial ability, but textiles with self-cleaning properties is also widely developed. The surfaces of textiles products from both natural and synthetic fiber can be modified to obtain self-cleaning with antibacterial textiles. Nylon fiber mostly used due to its superiority such as good electric conductivity, slight weight, good resistance against the corrosion and has good mechanical properties $^{1,2}$. Besides that, Nylon fiber is naturally hydrophobic so it used as socks, underwears, and sport shirt. $^{3}$

Self-cleaning textiles are obtained by duplicates the hydrophobicity properties of lotus leaves (Nelumbo nucifera). Self-cleaning textiles let trough the water so it can avoid the dirt stick to the textiles surfaces ${ }^{4}$. The hydrophobicity of textiles can be improved by adding silane compound which can reduce the surface energy of material. ${ }^{3-6}$

Nylon with antibacterial properties can be produced by using nanotechnology, especially nanoparticles. Nowadays, the study of nanoparticles not only about its utilization or application but also includes how to synthesize it ${ }^{7}$. Silver nanoparticles are the most popular nanoparticles which are used as an antibacterial antibacterial agent. Some previous study used a reduction method to synthesized silver nanoparticles.

Rasayan J. Chem., 12(3), 1352-1359(2019)

http://dx.doi.org/10.31788/RJC.2019.1235179

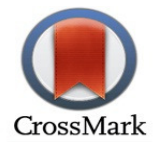


Chemical substances which already used as reductor were sodium citrate ${ }^{8}$, sodium borohydride $^{9}$ and ascorbatic acid ${ }^{10}$.

In this time, the preparation of silver nanoparticles using natural reductor (bio-reductor) is mostly increased. This method is quite cheap, environmentally friendly, and easy to do in the large scale industry, and also a very pure method. While chemical reductor is more expensive and harmful to living things and the environment.

In this study, the quality of Nylon fabric is enhanced by modified its surface with Hexadecyltrimethoxysilane (HDTMS) to obtain self-cleaning textiles and silver nanoparticles which prepared via bio-reduction method using banana peel extract (Musa paradisiaca Linn.) to produce antibacterial textiles. The hydrophobicity of Nylon fabrics can be analyzed by the sessile drop method. While measuring of clear zone around the sample is conducted to know antibacterial properties of Nylon towards Staphylococcus aureus (gram-positive) and Escherichia coli (gram-negative). ${ }^{5,6}$.

\section{Materials}

\section{EXPERIMENTAL}

Nylon fabric was collected from textiles store in Yogyakarta, silver nitrate (Merck), fresh banana peel (Musa paradisiaca Linn.), HDTMS (Merck), PVA (Merck), Nutrient Agar (Oxoid), Nutrient Broth (Oxoid), distilled water, ethanol 90\% (Merck), Acetone, Escherichia coli ATCC 35218 and Staphylococcus aureus from collection in Faculty of Medicine, UGM Yogyakarta Indonesia.

\section{Producing of Ag Nanoparticles by Using Banana Peel Extract (Musa paradisiaca Linn.)}

20 gram of fresh ripe banana peel (Musa paradisiaca Linn.) was washed with distilled water and put into $500 \mathrm{~mL}$ of beker glass. Added as much as $100 \mathrm{~mL}$ of aquadest into the beker glass and boiled until reached the constant temperature $\left(92{ }^{\circ} \mathrm{C}\right)$. Then the extract of banana peel was filtered using the Whatman No. 42. About $1 \mathrm{~mL}$ of the extract was poured into $40 \mathrm{~mL}$ of silver nitrate solution and mixed with $12 \mathrm{~mL}$ of $1 \%$ of PVA solution. To obtain colloidal silver nanoparticles, the solution stood for 3 hours until the color is constant. The colloid of $\mathrm{Ag}$ nanoparticle was characterized using spectrophotometer of UltraViolet-Visible from Shimadzu UV-2400 PC.

\section{Impregnation of Ag Nanoparticles on Nylon Fiber (Nylon-Ag)}

Nylon fabric with the size of $5 \times 5 \mathrm{~cm}^{2}$ was rinsed in distilled water for an hour then rinsed in acetone for an hour too. The fabric was dried in room temperature and put into $100 \mathrm{~mL}$ of Erlenmeyer which contain colloidal silver nanoparticle and was shaken by using a shaker with a velocity of 155 rpm during 24 hours. The fabric was continuously rinsed as long as 70 hours and then dried in room temperature.

\section{Modification of Nylon Fiber Using HDTMS Compound (Nylon-HDTMS)}

$4 \%$ of solution HDTMS was obtained by adding $10 \mathrm{~mL}$ of HDTMS into $250 \mathrm{~mL}$ of the flask and $90 \%$ of ethanol was added into the flask and then homogenized. The solution was stirred for 6 hours. Nylon and Nylon-Ag were rinsed in 4\% solution of HDTMS and shook with the velocity of $155 \mathrm{rpm}$ for an hour. The fabrics were dried at room temperature.

\section{Test of Contact-Angle}

The value of the contact angle was analyzed by using the sessile drop method. Each of the Nylon sample: Ny, Ny-Ag, Ny-HDTMS, Ny-Ag-HDTMS, and Ny-HDMTS-Ag was placed in the flat table. Then about $0.05 \mathrm{~mL}$ of water was dropped from the height of $1 \mathrm{~cm}$ from the sample. The bubble of water in the sample was captured by Canon EOS 700D camera. The photos that obtained were analyzed by Corel Draw Version X7 with Angular Dimension Tool so the value of contact angle automatically could be studied.

\section{Test of Inhibition Zone (Antibacterial Activity)}

Nutrient Agar (NA) and Nutrient Broth (NB) were dissolved in aquadest to obtain media. The bacteria of gram-negative (Escherichia coli ATCC 35218) and gram-positive (Staphylococcus aureus ATCC 25923) were rejuvenated in NA media and put in the incubator of $37{ }^{\circ} \mathrm{C}$ for 1440 minutes. All of the samples 
were circular-shaped by the paper hole puncher with a diameter of $\pm 0.5 \mathrm{~cm}$. The sample then sterilized by UV light in the Laminar Air Flow and put into the NA media.

The measurement of clear-zone using vernier caliper was conducted at an interval of 6 hours during 72 hours. The data of the diameter of the clear zone were analyzed by SPSS program version 19. Statistical test which used were Anova, Least Significant Different (LSD) and t-Independent. ANOVA test was used to know the influence of the type of sample, incubation time, also the influence sample and incubation time towards the antibacterial activity of Nylon against gram-positive and gram-negative bacteria. The LSD is a further Anova test to determine the significance of antibacterial activity between two types of samples. However, the test of t-independent to determine the significant difference of antibacterial activity for every sample in inhibiting between the growth of gram-negative and gram-positive bacteria.

\section{Physical Properties of The Colloidal Ag Nanoparticles}

\section{RESULTS AND DISCUSSION}

Banana (Musa paradisiaca Linn.) peel extract was obtained from the boiling process. The banana peel extract was separated by using filter paper of Whatman number 42 as showed by Fig.-1. After 3 hours, the colorless colloidal silver nanoparticles was turned to orange color. Color transformation of the colloidal silver nanoparticles indicated that silver nanoparticles were already formed. The colloid of $\mathrm{Ag}$ nanoparticles was analyzed by spectrophotometer of UltraViolet-Visible in the range 200-600 nm. While the blanko (silver nitrate solution) used the range of 190-200 $\mathrm{nm}$. The result of the characterization was shown in Fig.- 2. According to the Fig.-2, the maximum peak of silver nitrate solution appeared at the wavelength of $218.50 \mathrm{~nm}$ and its absorbance was 2.712. While the UV-Vis spectrum in the picture showed that there was a specific peak of silver nanoparticles at the wavelength of $440.50 \mathrm{~nm}$ and its absorbance was 0.471 .

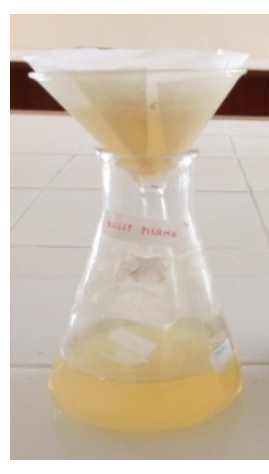

(a)

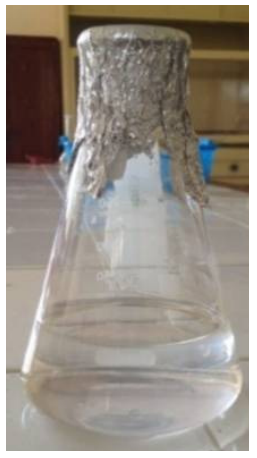

(b)

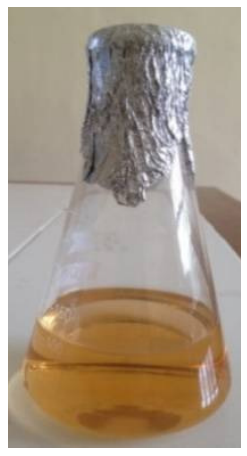

(c)

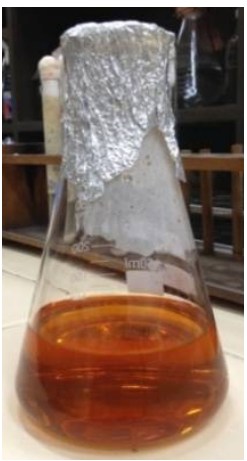

(d)

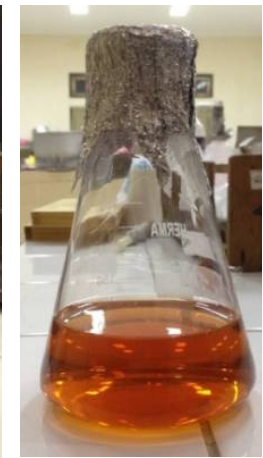

(e)

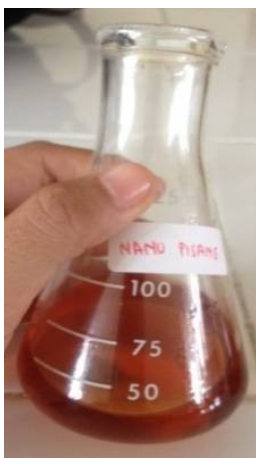

(f)

Fig.-1: Banana Peel Extract (a); The Mixture of Banana Peel Extract, Silver Nitrate Solution, and PVA Solution (b); Colloidal Silver Nanoparticles after 1 Hour, 2 Hours, 3 Hours (c, d, e); and after 1 Day (f)

In addition, there were three other peaks of silver nitrate that appeared at the wavelength of 240.50 , 214.50, and $207.00 \mathrm{~nm}$. Those three peaks indicated that not all of the $\mathrm{Ag}^{+}$were reduced to $\mathrm{Ag}^{0}$. $\mathrm{Banana}$ peel extract (Musa paradisiaca Linn.) contained some kind of secondary metabolite compounds such as flavonoid, terpenoid and tannin ${ }^{11}$. In this case, tannin has a role as a bio-reductor in silver nanoparticles formation. Color transformation during the process indicated that the reduction process of $\mathrm{Ag}^{+} \rightarrow \mathrm{Ag}^{0}$ was successfully done. Between the PVA and the Ag nanoparticles form complex compound by covalent bonds between the silver nanoparticles and oxygen atoms of PVA, which resulted in a lower concentration of free silver nanoparticles and a decreasing in the potential of electrode of the silver ion, and then increased up the reaction rate of silver ions to produce silver atoms during particle growth process $^{12}$. 


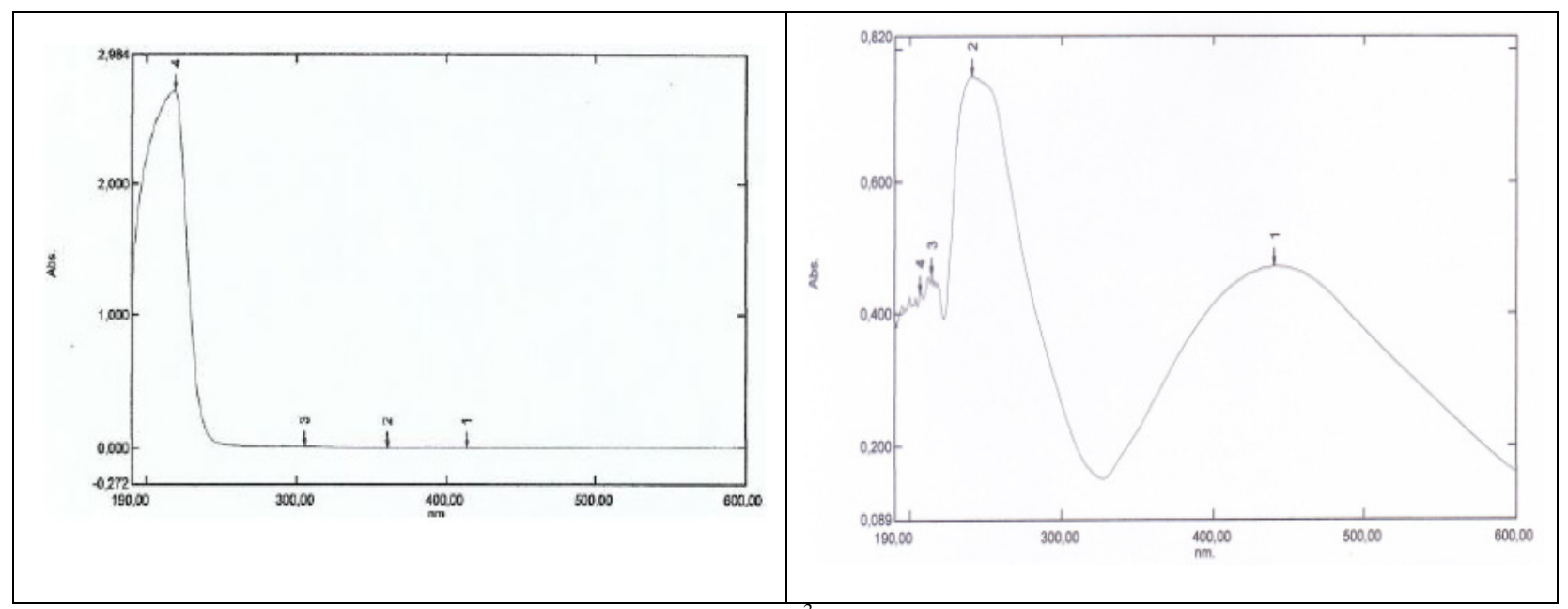

Fig.-2: The UV-Vis Spectra of $1.10^{-3} \mathrm{M} \mathrm{AgNO}_{3}$ (a) and Ag Nanoparticles (b)

Antibacterial Activity of Nylon against Gram-negative (Escherichia coli ATCC 35218) and Grampositive (Staphylococcus aureus ATCC 25923)

The diameter of the clear zone of Nylon fabrics against gram-negative bacteria during 24 hours of incubation time was shown by Fig.-3. The inhibition zone which formed circa of Nylon showed that the bacteria did not grow in that area.

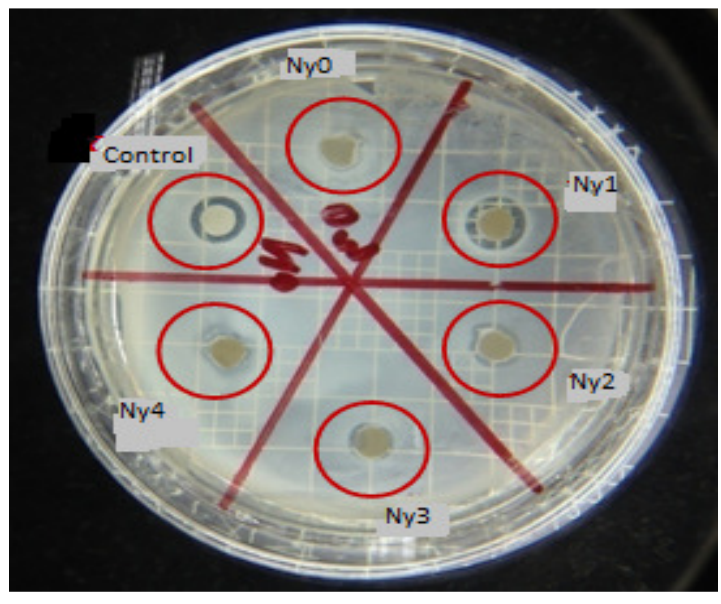

(a)

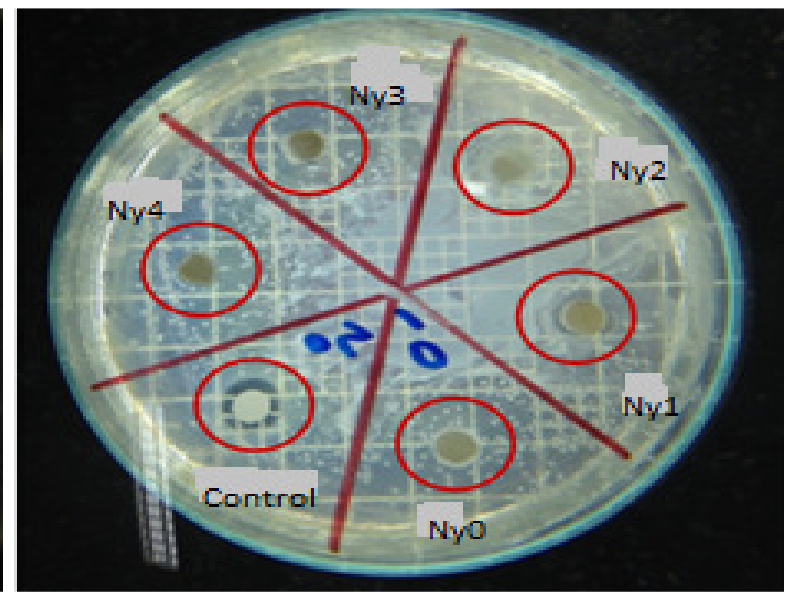

(b)

Fig.-3: Diameter of Clear Zone of Nylon Fabrics against Escherichia coli (a) and Staphylococcus aureus ATCC 25923 (b)

Antibacterial activity of nylon could be seen since 6 hours of incubation time and all of the samples had antibacterial properties to inhibit the growth of E.coli ATCC 35218. Data from the measurement of the inhibition zone during 72 hours of incubation were presented in Table-1.

The sample of Nylon-Ag at the 54 hours of incubation time has the greatest diameter, that is $9.70 \mathrm{~mm}$. This adduces that silver nanoparticles have a good ability to inhibit the growth of bacteria even though it already impregnated in the Nylon fabrics. Table- 2 shows the data of clear zone that formed by nylon against gram-positive bacteria ( $S$. aureus ATCC 25923). The greatest diameter of the inhibition zone is Nylon-Ag at the 66 and 72 hours of incubation time, that is $8.50 \mathrm{~mm}$.

The mechanism of bacterial growth inhibition by silver nanoparticles begins with releasing the ion of $\mathrm{Ag}^{+}$ which then interact with thiol sulfihydryl $(-\mathrm{SH})$ which are contained inside of the protein in membrane plasma. Furthermore, the cation of $\mathrm{H}^{+}$is substituted by the ion of $\mathrm{Ag}^{+}$in the thiol sulfihydryl and the 
stable S-Ag are formed so the protein becomes inactive and the permeability of membrane will be decline. The silver compound will penetrate the cell wall and change the structure of bacterial DNA so that the bacterial will be died ${ }^{13}$.

Table-1: Antibacterial Activity of Nylon against Gram-negative Bacteria (E.coli ATCC 35218)

\begin{tabular}{c|c|c|c|c|c}
\hline \multirow{2}{*}{$\begin{array}{c}\text { Time } \\
\text { (hours) }\end{array}$} & \multicolumn{5}{|c}{ Diameter of inhibition zone (mm) } \\
\cline { 2 - 6 } & Ny0 & Ny1 & Ny2 & Ny3 & Ny4 \\
\hline 6 & 7.20 & 8.00 & 8.10 & 7.40 & 7.00 \\
\hline 12 & 6.30 & 7.00 & 7.80 & 7.00 & 6.60 \\
\hline 18 & 6.50 & 7.20 & 7.30 & 7.20 & 6.50 \\
\hline 24 & 0.00 & 7.20 & 7.10 & 6.80 & 6.60 \\
\hline 30 & 7.10 & 7.70 & 7.20 & 7.30 & 6.70 \\
\hline 36 & 7.30 & 8.40 & 7.50 & 7.60 & 7.70 \\
\hline 42 & 0.00 & 7.20 & 6.90 & 6.90 & 6.50 \\
\hline 48 & 6.80 & 7.90 & 7.50 & 7.30 & 6.90 \\
\hline 54 & 7.20 & 9.70 & 7.80 & 6.90 & 7.00 \\
\hline 60 & 0.00 & 7.30 & 7.10 & 6.80 & 6.60 \\
\hline 66 & 6.30 & 7.30 & 7.60 & 6.90 & 6.50 \\
\hline 72 & 5.90 & 7.90 & 0.00 & 5.50 & 5.60 \\
\hline
\end{tabular}

Table-2: Antibacterial Activity of Nylon against Gram-positive Bacteria (S. aureus ATCC 25923)

\begin{tabular}{c|c|c|c|c|c}
\hline \multirow{2}{*}{$\begin{array}{c}\text { Time } \\
\text { (hours) }\end{array}$} & \multicolumn{5}{|c}{ Diameter of clear zone $(\mathrm{mm})$} \\
\cline { 2 - 6 } & Ny0 & Ny1 & Ny2 & Ny3 & Ny4 \\
\hline 6 & 7.40 & 8.00 & 7.90 & 7.10 & 7.00 \\
\hline 12 & 7.10 & 8.10 & 7.70 & 7.00 & 6.90 \\
\hline 18 & 6.50 & 7.20 & 6.90 & 6.80 & 6.70 \\
\hline 24 & 6.90 & 7.40 & 6.90 & 6.80 & 6.80 \\
\hline 30 & 7.20 & 7.50 & 7.80 & 7.00 & 7.00 \\
\hline 36 & 7.00 & 7.90 & 7.90 & 7.00 & 7.00 \\
\hline 42 & 6.20 & 7.10 & 6.60 & 6.60 & 6.30 \\
\hline 48 & 0.00 & 8.10 & 8.10 & 6.90 & 6.70 \\
\hline 54 & 6.90 & 8.00 & 7.60 & 7.30 & 6.90 \\
\hline 60 & 0.00 & 6.30 & 0.00 & 6.20 & 5.90 \\
\hline 66 & 0.00 & 8.50 & 8.10 & 7.30 & 7.30 \\
\hline 72 & 0.00 & 8.50 & 8.20 & 7.20 & 7.50 \\
\hline
\end{tabular}

The ANOVA test result is shown by Table-3. While the result of LSD test is shown by Table-4. The incubation time influences the antibacterial activity of nylon in inhibiting the growth of $S$. aureus and E.coli, respectively. The antibacterial activities of nylon are also affected by the type of nylon sample. However, the antibacterial activity of nylon in inhibiting the growth of E.coli is affected by both, namely incubation time and the type of sample. Therefore, modification of nylon fabrics by silver nanoparticles, HDTMS compound, and the combination between both of them significantly affects inhibition activity against E.coli and S.aureus.

Based on the Table-4, the interaction between two sample Ny0-Ny1, Ny0-Ny3, Ny0-Ny4 and Ny2-Ny3 have a significant difference in inhibiting the growth of $E$. coli. It means that modification of nylon fabrics by using silver nanoparticles, and the combination between silver nanoparticles and HDTMS can affect antibacterial activity of the fabircs against E.coli. While two types of samples that significantly 
affecting the antibacterial activity of Nylon fabrics against $S$. aureus are Ny0-Ny1, Ny0-Ny2, Ny0-Ny3, Ny0-Ny4, Ny1-Ny2, Ny1-Ny3, and Ny2-Ny4. It means that modification of nylon fabrics by using silver nanoparticles, HDTMs, and the combination between silver nanoparticles and HDTMS, and also HDTMS and silver nanoparticles can affect antibacterial activity of the fabircs against Staphylococcus aureus.

The result of the t-independent test shows that all of the samples have the same ability in inhibiting the growth of E.coli and S.aureus (Table-5). Nylon fabric which modified by HDTMS compound also shows its antibacterial activity against E.coli and $S$. aureus even though HDTMS compound is not an antibacterial agent. The characteristic of HDTMS compound is like detergent, that is consist of hydrophilic and hydrophobic site. Hydrophilic and hydrophobic sites of detergent have ability to the damaged cytoplasmic membrane of bacteria so this bacteria would be killed ${ }^{14}$.

All samples having excellent antibacterial activity against gram-positive and gram-negative bacteria. In this paper, Nylon after modification with silver nanoparticles has shown most inhibition to the bacteria growth by the formation of reactive oxygen species and accumulation of nanoparticles. Nanoparticles act as bactericidal and bacteriostatic agents ${ }^{15}$.

Table-3: The Effect of Incubation Time, Type of Sample, and Interaction between Time and Sample towards Antibacterial Activity of Nylon against E. coli and S.aureus

\begin{tabular}{|c|c|c|c|c|c|}
\hline \multicolumn{6}{|c|}{ E. coli ATCC 35218} \\
\hline Variable & Sum of Squares (SS) & $\begin{array}{c}\text { Degree Free } \\
\text { (df) }\end{array}$ & $\begin{array}{c}\text { Mean Square } \\
\text { (MS) }\end{array}$ & $\mathrm{F}$ value & Conclusion \\
\hline Incubation Time & 2.553 & 11 & 0.232 & 5.023 & 0.000 \\
\hline Nylon Fabric & 0.803 & 4 & 0.201 & 4.344 & 0.003 \\
\hline Time* Nylon & 4.532 & 44 & 0.103 & 2.229 & 0.000 \\
\hline \multicolumn{6}{|c|}{ S.aureus ATCC 25923} \\
\hline Variable & Sum of Squares (SS) & $\begin{array}{c}\text { Degree Free } \\
(\mathrm{df})\end{array}$ & $\begin{array}{c}\text { Mean Square } \\
\text { (MS) }\end{array}$ & $\mathrm{F}$ value & Conclusion \\
\hline Incubation Time & 2.705 & 11 & 0.246 & 4.042 & 0.000 \\
\hline Nylon Fabric & 4.672 & 4 & 1.168 & 19.197 & 0.000 \\
\hline Time * Nylon & 2.416 & 44 & 0.055 & 0.902 & 0.644 \\
\hline
\end{tabular}

Table-4: Interpretation of LSD Test Results between the Type of Sample against Escherichia coli and Staphylococcus aureus ATCC 25923

\begin{tabular}{c|c|c}
\hline \multirow{2}{*}{$\begin{array}{c}\text { The type of Nylon } \\
\text { sample }\end{array}$} & \multicolumn{2}{|c}{ Conclusion } \\
\cline { 2 - 3 } & E. coli & S. aureus \\
\hline Ny0 - Ny1 & Significant & Significant \\
\hline Ny0 - Ny2 & Not significant & Significant \\
\hline Ny0 - Ny3 & Significant & Significant \\
\hline Ny0 - Ny4 & Significant & Significant \\
\hline Ny1 - Ny2 & Not significant & Significant \\
\hline Ny1 - Ny3 & Not significant & Significant \\
\hline Ny1 - Ny4 & Not significant & Not significant \\
\hline Ny2 - Ny3 & Significant & Not significant \\
\hline Ny2 - Ny4 & Not significant & Significant \\
\hline Ny3 - Ny4 & Not significant & Not significant \\
\hline
\end{tabular}

\section{The Contact Angle of Nylon}

The contact angle of nylon without modification and which modified by silver nanoparticles, HDTMS compound, and also the combination of both of silver nanoparticles and HDTMS compound are presented in Fig.-4.

Table-5: Interpretation of t-Independent Test Result of Nylon Fabrics against Escherichia coli and Staphylococcus aureus ATCC 25923

\begin{tabular}{c|c}
\hline Nylon & t-Independent \\
\hline Ny0 & No difference \\
\hline
\end{tabular}


RASĀYAN J. Chem.

Vol. 12 | No. 3 |1352 - 1359| July - September | 2019

\begin{tabular}{l|l}
\hline Ny1 & No difference \\
\hline Ny2 & No difference \\
\hline Ny3 & No difference \\
\hline Ny4 & No difference \\
\hline
\end{tabular}

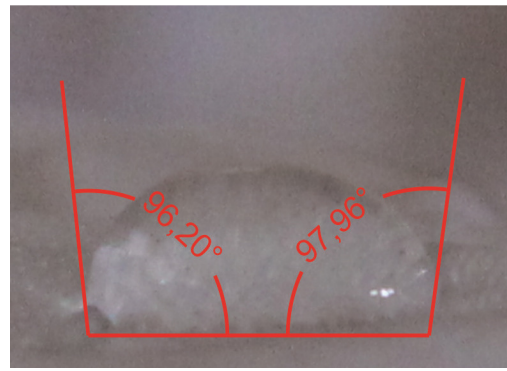

$\Theta=97.08^{\circ}$

(a)

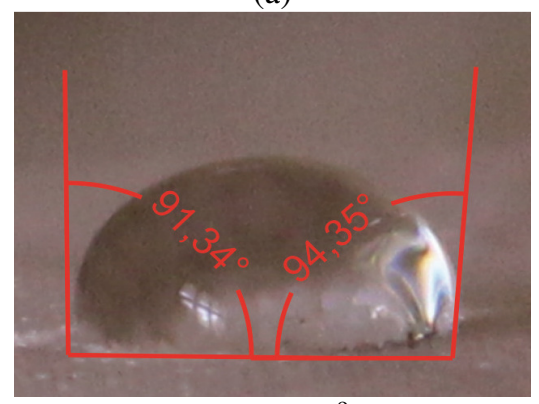

$\Theta=92.85^{\circ}$

(d)

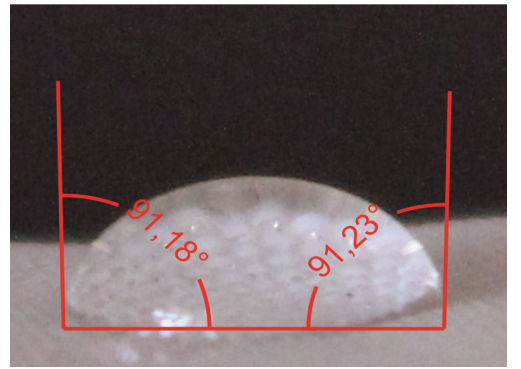

$\Theta=91.21^{\circ}$

(b)

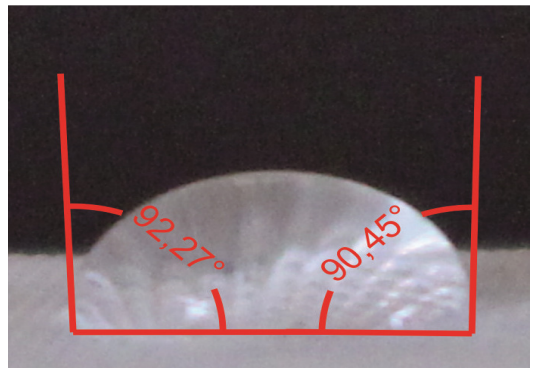

$\Theta=91.36^{\circ}$

(c)

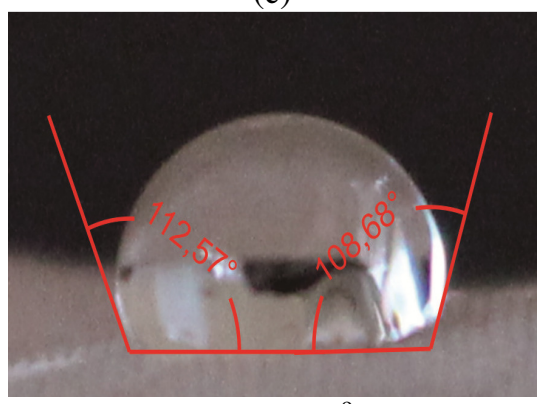

$\Theta=110.63^{\circ}$

(e)

Fig.-4: The Contact Angle of Ny0 (a), Ny1 (b), Ny2 (c), Ny3 (d), and Ny4 (e)

Sample Ny4 has the greatest contact angle, that is $110.63^{\circ}$. Sample Ny4 was modified by HDTMS compound and continued with the adding of silver nanoparticles. This result proved that HDTMS compound can increase the contact angle value by decrease the surface energy of nylon ${ }^{4}$. HDTMS compound consists of the head section which is hydrophilic, and its tail is hydrophobic. In the head section, there is a silicon atom which bonded with three functional groups of methoxy $\left(-\mathrm{OCH}_{3}\right)$, while its tail is consist of a long alkyl group $\left(-\mathrm{C}_{16} \mathrm{H}_{33}\right)$. This compound can decrease the surface energy of material by interacting with the surface of it. Before that, HDTMS compound will hydrolize and yield the $-\mathrm{OH}$ group which will interact with $-\mathrm{CONH}-$ group in the surface of Nylon forming $\mathrm{Si}-\mathrm{O}-\mathrm{N}$. It will cause the tail which is long hydrophobic alkyl group in the outside of Nylon surface so it becomes waterproof ${ }^{4}$, ${ }^{16}$. Other than that, the HDTMS acts like a surfactant consisting of a hydrophobic part that will protect Nylon fabrics interacting with silver nanoparticles. The surfactant acts stabilizer of nanoparticles ${ }^{17}$. It was caused by the hydroxyls from the hydrolyzed HDTMS decrease the free energy of Gibbs on the surface of the Nylon, so the surfactant can work optimally ${ }^{18}$.

Sample Ny3 also modified by silver nanoparticles and HDTMS too, but silver nanoparticles were impregnated first and continued by the adding of HDTMS compound. The contact angle of sample Ny3 is lower than sample Ny4 due to the nitrogen atom in the Nylon fabric has already interacted with -Ag so HDTMS compound can't interact with the surface of Nylon perfectly.

\section{CONCLUSION}

Silver nanoparticles were successfully prepared by using banana peel extract (Musa paradisiaca Linn.) as indicated by the maximum peak at the wavelength of $440.50 \mathrm{~nm}$. The Nylon fabric which modified by silver nanoparticles showed the highest antibacterial activity against gram-positive and gram-negative bacteria. The incubation time and the type of sample affected the antibacterial activity of Nylon fabrics against Escherichia coli and Staphylococcus aureus. While the interaction between the type of sample 
and the incubation time just affected the antibacterial activity against E.coli. The Nylon-Ag has a higher antibacterial activity than Nylon without modification. All of the Nylon samples have the same antibacterial activity in inhibiting the growth of gram-positive and gram-negative bacteria. Nylon fabric which modified by HDTMS compound and continued with the adding of Ag nanoparticles has the greatest $\Theta$, that was $110.63^{\circ}$

\section{ACKNOWLEDGMENT}

We express our deepest gratitude to Ministry of Research, Technology and Higher Education of Republic of Indonesia through "Applied Research Grant" the year 2018-2019 and "Overseas Seminar Assistance (BSLN 2019)" for research funding and financial assistance to attend a conference abroad (ICSET 2019

\section{REFERENCES}

1. M. Montazer and K. Z Nia, Journal of Materials Science and Engineering, 56(1), 341(2015), DOI:10.1016/j.msec.2015.06.044

2. S. Bose and P. A. Mahanwar, Journal of Minerals \& Materials Characterization \& Engineering, 3(2), 65(2004), DOI: 10.4236/jmmce.2004.32007

3. E. Rohaeti and A. Rakhmawati, Oriental Journal of Chemistry, 33(6), 2905(2017), DOI: $10.13005 /$ ojc/330625

4. H. Wang, J. Ding, T. Lin and X. Wang, Research Journal of Textile and Apparel, 14, 2 (2010), DOI:10.1557/JMR.2010.0169

5. E. Rohaeti and A. Rakhmawati, In Proceeding of International Conference on Research, Implementation and Education of Mathematics and Sciences, Yogyakarta, Indonesia, pp. 020010-1020010-9 (2017), DOI: 10.1063/1.4995096

6. M. S. Khalilabad and M. E. Yazdanshenas, Cellulose, 20(6), 3039(2013), DOI: 10.1007/s10570013-0040-2

7. V. Gopinath, D. Mubarak Ali, S. Priyadarshini, N. M. Priyadharsshini, N. Thajuddin and P. Velusamy, Journal of Colloids and Surfaces Biointerfaces, 96(1), 69(2012), DOI:10.1016/j.colsurfb.2012.03.023

8. H. A. Ariyanta, S. Wahyuni and S. Priatmoko, Indonesian Journal of Chemical Science, 3, 1 (2014)

9. A. Kumar, H. Joshi, R. Pasricha, A. B. Mandale and M. Sastry, Journal of Colloid and Interface Science, 264(2), 396 (2003), DOI: 10.1016/S0021-9797(03)00567-8

10. V. R. Chaudhari, S. K. Haram and S. K. Kulshreshtha, Journal of Colloids and Surfaces A, 301, 1 (2007), DOI:10.1007/s10895-014-1348-5

11. F.M.T Supriyanti, H. Suanda and R. Rosdiana, In Proceeding Seminar Nasional Kimia dan Pendidikan Kimia VII, Solo, Indonesia, pp. 1-9 (2015).

12. H Hei, H He, R Wang, $X$ Liu and $G$ Zhang, Soft Nanoscience Letters, 2(3), 7(2012), DOI: $10.4236 / \mathrm{snl} .2012 .23007$

13. Q. L. Feng, J. Wu, G. Q. Chen, F. Z. Cui, T. N. Kim and J.O. Kim, Journal of Biomedical Materials Research, 52(4), 662(2000), DOI: 10.1002/1097-4636(20001215)52:4\%3C662::AIDJBM10\%3E3.0.CO;2-3

14. B. P. Rama, P. S. Prajna, V. P. Menezez and P. Shetty, Advance in Bioresearch, 2, 2 (2011)

15. A. Raj and R. Lawerence, Rasayan Journal of Chemistry, 11(3), 1339(2018), DOI: $10.31788 /$ RJC.2018.1132009

16. A. Dhotel, Thesis, Department of Mechanical and Materials Enginering, University of Nebraska, Lincoln, Nebraska (2010).

17. F. C. Nalle, R. Wahid, I. O. Wulandari and A. Sabarudin, Rasayan Journal of Chemistry, 12(1), 14(2019), DOI:10.31788/RJC.2019.1214082

18. T. D. Wahyuningsih, Y. S. Kurniawan, S. Amalia, T. A. K. Wardhani and C. E. S. Muriningsih, Rasayan Journal of Chemistry, 12(2), 741(2019), DOI:10.31788/RJC.2019.1225140

[RJC-5179/2019] 